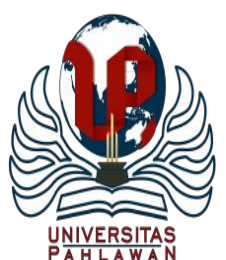

Edukatif : Jurnal Ilmu Pendidikan Volume 3 Nomor 4 Tahun 2021 Halm 1344 - 1353

EDUKATIF: JURNAL ILMU PENDIDIKAN

Research \& Learning in Education

https://edukatif.org/index.php/edukatif/index

\title{
Metode Penyebaran Agama Islam Sunan Gunung Djati dalam Perspektif Pendidikan Islam Modern
}

\author{
Asep Supriatna ${ }^{1 凶}$, Rini Novianti Yusuf ${ }^{2}$, Vina Febiani Musyadad ${ }^{3}$, Alfian Syach $^{4}$, \\ Yogha Zulfian Iskandar ${ }^{5}$ \\ STIT Rakeyan Santang, Indonesia ${ }^{1,2.3 .4,5}$ \\ E-mail : aasepstea@gmail.com ${ }^{1}$, rininovi48@gmail.com ${ }^{2}$, vinamusyadad@gmail.com ${ }^{3}$, \\ alfyansyach38@gmail.com ${ }^{4}$, zulvianyogha@gmail.com ${ }^{5}$
}

\begin{abstract}
Abstrak
Pendidikan Islam menurut pemikiran Sunan Gunung Djati Terutama caranya berdakwah, yang dianggap berbeda dengan metode para wali yang lain dimana Dia berani memadukan dakwah dengan seni budaya yang mengakar di masyarakat. Masalah yang dibahas dalam penelitian ini meliputi: Konsep pendidikan menurut Sunan Gunung Djati; Konsep pendidikan Islam modern; dan Relevansi terhadap Konsep Pendidikan Menurut Sunan Gunung Djati terhadap Pendidikan Modern. Penelitian ini bertujuan untuk : Mengetahui konsep pendidikan menurut Sunan Gunung Djati; Mengetahui Konsep Pendidikan Menurut Pendidikan Islam; dan Mengetahui Relevansi terhadap Konsep Pendidikan Menurut Sunan Gunung Djati terhadap Pendidikan Modern. Metode Penelitian ini termasuk dalam jenis penelitian bibliografis. Hasil dari penelitian yang dilakukan adalah bahwa penyebaran Agama Islam yang dilakukan Sunan Gunung Djati terhadap perkembangan Islam di Jawa sangat besar sekali. Adanya kerajaan Islam di Demak dan Banten merupakan beberapa contohnya. Tak kalah pentingnya lagi kontribusi Syarif Hidayatullah pada perkembangan Islam di Jawa Barat dengan cara dakwah dengan damai, mulai dari Kuningan, Indramayu, Majalengka, Cianjur, Garut, Ciamis, Sumedang, bahkan Jayakarta (Betawi).
\end{abstract}

Kata kunci: Metode, Perspektif, Sunan Gunung Djati, Pendidikan Islam.

\begin{abstract}
Islamic education according to the thoughts of Sunan Gunung Djati, especially his method of preaching, which is considered different from the methods of other saints where he dares to combine da'wah with cultural arts that are rooted in society. The problems discussed in this study include: The concept of education according to Sunan Gunung Djati; The concept of modern Islamic education; and the relevance of the concept of education according to Sunan Gunung Djati to modern education. This study aims to: Know the concept of education according to Sunan Gunung Djati; Knowing the Concept of Education according to Islamic Education; and Knowing the Relevance of the Concept of Education by Sunan Gunung Djati to Modern Education. This research method is included in the type of bibliographic research. The results of the research conducted were that the spread of Islam by Sunan Gunung Djati to the development of Islam in Java was enormous. The existence of Islamic kingdoms in Demak and Banten are some examples. No less important is the contribution of Syarif Hidayatullah to the development of Islam in West Java by means of peaceful preaching, starting from Kuningan, Indramayu, Majalengka, Cianjur, Garut, Ciamis, Sumedang, and even Jayakarta (Betawi).
\end{abstract}

Keywords: Method, Perspective, Sunan Gunung Djati, Islamic Education.

Copyright (c) 2021 Asep Supriatna, Rini Novianti Yusuf, Vina Febiani Musyadad, Alfian Syach, Yogha Zulvian Iskandar

$\triangle$ Corresponding author

Email : aasepstea@gmail.com

DOI : https://doi.org/10.31004/edukatif.v3i4.478

ISSN 2656-8063 (Media Cetak)

ISSN 2656-8071 (Media Online) 
1345 Metode Pembayaran Agama Islam Sunan Gunung Djati dalam Perspektif Pendidikan Islam Modern-Asep Supriatna, Rini Novianti Yusuf, Vina Febiani Musyadad, Alfian Syach, Yogha Zulvian Iskandar

DOI : https://doi.org/10.31004/edukatif.v3i4.478

\section{PENDAHULUAN}

Pendidikan Islam merupakan penataan individual dan sosial yang dapat menyebabkan seseorang tunduk dan patuh pada Islam serta menerapkannya secara sempurna di dalam kehidupan individu dan masyarakat. Berdasarkan makna ini maka pendidikan Islam berupaya untuk mempersiapkan diri manusia agar dapat melaksanakan amanat yang dipikulnya yaitu sebagai khalifah Allah SWT yang bertugas memakmurkan bumi, sebagai hamba Allah SWT berkewajiban untuk mengabdi dan beribadah semata-mata hanya kepada Allah SWT.

Islam sebagai agama yang mengandung konsep-konsep, wawasan-wawasan, dan ide-ide dasar yang memberi inspirasi terhadap pemikiran umat manusia sekaligus sebagai sistem peradaban mengisyaratkan betapa pentingnya pendidikan. Isyarat ini dijelaskan dari berbagai muatan dalam konsep ajarannya salah satu diantaranya melalui pendekatan filosofis, ilmu pendidikan Islam dapat diartikan sebagai studi tentang proses kependidikan yang didasari oleh nilai-nilai Islam menurut konsepsi filosofis yang bersumberkan pada $\mathrm{Al}$ Qur'an dan Sunnah Nabi Muhammad SAW (Nata, 2016).

Pendidikan sebagai suatu proses dalam pandangan filsafat pendidikan Islam, sebagaimana tidak dapat dilepaskan dari keterkaitan dengan fitrah manusia sebagai makhluk ciptaan Allah SWT. Dengan demikian pendidikan pada hakikatnya adalah rangkaian bimbingan dan pengarahan hidup manusia berupa kemampuankemampuan dasar (potensi fitrah) dan kemampuan ajar (Intervensi), sehingga terjadi perubahan dalam kehidupan pribadinya baik dalam statusnya sebagai makhluk individu sosial serta hubungannya dengan alam sekitar dimana ia hidup. Proses tersebut senantiasa harus berada dalam nilai-nilai Islam yaitu nilai-nilai yang melahirkan norma-norma Syari'at dan Akhlaq al Karimah.

Pendidikan Islam adalah suatu sistem kependidikan yang mencakup seluruh aspek kehidupan yang dibutuhkan oleh hamba-hamba Allah SWT (Imelda, 2017). Menurut Solicin bahwa membicarakan tentang Wali Sanga berarti membicarakan mengenai Islam di tanah Jawa. Oleh karena Wali Sanga lah yang mempelopori dakwah Islam di bumi Jawa. Wali Sanga dianggap sebagai tokoh-tokoh sejarah kharismatik yang membumikan Islam di tanah Jawa yang sebelumnya berkembang bersama tradisi Hindu-Budha (Tajuddin, 2017) Kata wali berasal dari bahasa Arab itu artinya dekat atau kerabat, atau teman. Dalam AlQur'an istilah ini disebutkan dalam surat Yunus : 62 dan Al-Baqarah : 257.

Menurut (Purwadi, 2012) kata "wali" menurut istilah, ialah sebutan bagi orang-orang Islam yang dianggap keramat, mereka adalah penyebar agama Islam. Mereka dianggap manusia suci kekasih Allah, orang-orang yang sangat dekat dengan Allah, yang dikaruniai tenaga ghaib, mempunyai kekuatan-kekuatan batin yang sangat berlebih, mempunyai ilmu yang sangat tinggi, sakti berjaya-kejiwaan.

Menurut Hadiwiyono, kata sanga menurut pendapat Mohammad Adnan adalah perubahan dari kata sana yang berasal dari kata Arab "tsana" berarti sama dengan mahmud yang terpuji. Jadi Wali Sanga artinya wali-wali terpuji. Pendapat Raden Tanoyo (pengarang kitab Wali Sanga). Hanya saja Tanoyo mengartikan sana bukan hanya terpuji tetapi tempat (Purwadi, 2012).

Di antara Wali Sanga itu mereka adalah Maulana Malik Ibrahim, Sunan Ampel, Sunan Giri, Sunan Bonang, Sunan Drajat, Sunan Kalijaga, Sunan Kudus, Sunan Muria, serta Sunan Gunung Djati. Mereka tidak hidup pada saat yang persis bersamaan. Namun satu sama lain mempunyai keterkaitan erat, bila tidak dalam ikatan darah juga dalam hubungan guru-murid (Rahimsah, $2002: 5$ ).

Masing-masing tokoh tersebut mempunyai peran yang unik dalam penyebaran Islam. Mulai dari Maulana Malik Ibrahim yang menempatkan diri sebagai "tabib" bagi kerajaan Hindu Majapahit; Sunan Giri yang disebut para kolonialis sebaagai "paus dari Timur" hingga Sunan Gunung Djati yang mencipta karya Tajug (Purwadi, 2003: 73).

Tokoh wali yang sangat banyak mengandung misteri adalah Sunan Gunung Djati. Pada era Syarif Hidayatullah atau lebih dikenal dengan gelar Sunan Gunung Djati dapat dikatakan sebagai era keemasan 
1346 Metode Pembayaran Agama Islam Sunan Gunung Djati dalam Perspektif Pendidikan Islam Modern-Asep Supriatna, Rini Novianti Yusuf, Vina Febiani Musyadad, Alfian Syach, Yogha Zulvian Iskandar

DOI : https://doi.org/10.31004/edukatif.v3i4.478

(Golden Age) perkembangan Islam di Cirebon (Firmanto, 2015). Sebelum Syarif Hidayatullah, Cirebon dipimpin oleh Pangeran Cakrabuana (1447-1479) merupakan rintisan pemerintahan berdasarkan asas Islam, dan setelah Syarif Hidayatullah, pengaruh para penguasa Cirebon masih berlindung di balik kebesaran nama Syarif Hidayatullah.

Berangkat dari uraian tersebut diatas, penulis merasa sangat tertarik dan berminat untuk mengadakan studi secara mendalam tentang pendidikan Islam menurut pemikiran Sunan Gunung Djati sebagai objek kajian utama dalam penelitian. Terutama caranya berdakwah, yang dianggap berbeda dengan metode para wali yang lain. Dia berani memadukan dakwah dengan seni budaya yang mengakar di masyarakat. Ia tidak melakukan konfrontasi dengan budaya yang mengakar di masyarakat. Ia tidak melakukan konfrontasi dengan budaya masyarakat yang ada melainkan dengan "tapa geli" (mengikuti aliran air) dengan kebiasaan yang berlaku dan memberi baju Islam atau memberi pesan-pesan keislaman. Dengan demikian andil dan peranan Islam dalam membentuk kebudayaan Islam di Indonesia pada masa lalu hingga sekarang sangat besar, bahkan telah memberikan corak khusus bagi pendidikan Islam.

Berdasarkan rasionalitas dan realitas di atas, peneliti tertarik untuk meneliti bagaimana Metode Penyebaran Agama Islam yang dilakukan oleh Sunan Gunung Djati Dalam Perspektif Pendidikan Islam Modern. Sehigga bisa menjadi sebuah problema yang perlu dikaji dan diteliti.

\section{METODE PENELITIAN}

Penelitian ini menggunakan pendekatan kualitatif. Pendekatan kualitatif desainnya bersifat umum, dan berubah-ubah atau berkembang sesuai dengan situasi di lapangan. Sesuai dengan penjelasan menurut (Sugiyono, 2011) bahwa metode ini disebut dengan metode interpretive karena data hasil penelitian lebih berkenaan dengan interpretasi terhadap data yang ditemukan di lapangan. Kemudian, menurut (Putra \& Lisnawati, 2012) menyebutkan desain penelitian kualitatif biasanya bersifat global, tidak terperinci, tidak pasti dan sangat fleksibel. Dengan demikian desain hanya digunakan sebagai asumsi untuk melakukan penelitian, oleh karena itu desain pada penelitian kualitatif bersifat fleksibel dan terbuka. Sehingga pendekatan kualitatif dengan studi deskriptif merupakan pilihan yang tepat dalam penelitian ini. Menurut (Arikunto, 2013) studi deskriptif yaitu mengumpulkan data sebanyak-banyaknya mengenai faktor-faktor yang merupakan pendukung terhadap penelitian. Pada penelitian ini peneliti melakukan eksplorasi, menggambarkan dengan tujuan untuk dapat menerangkan dan memprediksi terhadap suatu gejala yang berlaku atas dasar data yang diperoleh dari lapangan.

Adapun jenis penelitian yang digunakan peneliti adalah library research atau penelitian kepustakaan. (Subagyo, 2015) menjelaskan yang dimaksud penelitian kepustakaan sebagai berikut: Penelitian yang menjadikan data-data kepustakaan sebagai teori untuk dikaji dan ditelaah dalam memperoleh hipotesa atau konsepsi untuk mendapatkan hasil yang objektif. Dengan jenis ini informasi dapat diambil secara lengkap untuk menentukan tindakan ilmiah dalam penelitian sebagai instrumen penelitian memenuhi standar penunjang penelitian. Dalam hal ini adalah penyebaran agama Islam yang dilakukan oleh Sunan Gunung Djati dalam perspektif Pendidikan Islam Modern. Riset kepustakaan ini dalam rangka mencari data yang valid agar dapat digunaakan untuk mengumpulkaan data-data yang penulis maksudkan serta pembahasan dan penganalisaannya secara sistematis.

Sumber data tersebut dapat dibagi menjadi dua, yaitu sumber data primer dan sumber data sekunder. Sumber data primer yaitu buku karya Purwadi tentang "Sejarah Sunan Gunung Djati Sintesis Ajaran Wali Sanga" yang berisi tentang sejarah perjuangan Sunan Gunung Djati hingga akhir hayatnya. Buku karya Widji Saksono tentang "Mengislamkan tanah Jawa telaah atas metode dakwah Walisongo" yang berisi tentang metode dakwah Sunan Gunung Djati, alat dan fasilitas dakwah. Buku karya Achmad Chodjim tentang "Mistik dan makrifat Sunan Gunung Djati ” yang berisi tentang sejarah singkat Sunan Gunung Djati, dan syariat. Buku 
1347 Metode Pembayaran Agama Islam Sunan Gunung Djati dalam Perspektif Pendidikan Islam Modern- Asep Supriatna, Rini Novianti Yusuf, Vina Febiani Musyadad, Alfian Syach, Yogha Zulvian Iskandar

DOI : https://doi.org/10.31004/edukatif.v3i4.478

karya Ridin Sofwan tentang "Islamisasi dai Jawa Walisongo penyebar Islam di Jawa menurut penuturan babad" yang berisi tentang sasaran dakwah, tujuan dakwah, dan metode dakwah. Sumber data sekunder meliputi : Ilmu Pendidikan Islam, Pendidikan Agama Islam, Pendidikan Islam di Rumah, Sekolah, dan Masyarakat, Filsafat Pendidikan Islam, dan lain-lain.

Pengumpulan data dalam penelitian ini dengan cara mengumpulkan bahan-bahan bacaan atau pustaka yang terdiri dari dokumen-dokumen, majalah-majalah, dan buku-buku yang berisi tentang Sunan Gunung Djati seperti ini disebut Metode Dokumentasi (Arikunto, 2013) yaitu mencari dan menggali data dari bahanbahan bacaan atau pustaka yang berkaitan dengan penyebaran agama Islam yang dilakukan oleh Sunan Gunung Djati dalam perspektif Pendidikan Islam Modern.

Data yang terkumpul dalam penelitian ini dianalisis dengan metode Content Analysis atau metode Kajian Isi. Menurut Holsti dikutip dari (Moleong, 2019) kajian isi adalah teknik apapun yang digunakan untuk menarik kesimpulan melalui usaha menemukan karakteristik pesan dan dilakukan secara obyektif dan sistematis.

\section{HASIL DAN PEMBAHASAN PENELITIAN}

Ada beberapa tokoh Walisanga yang ada di pulau Jawa, antara lain : Syeikh Maulana Malik Ibrahim berada di Gresik; Sunan Ampel di Surabaya; Sunan Giri di Gresik Sunan Bonang di Tuban; Sunan Drajat; Sunan Gunung Jati diCirebon; Sunan Kudu di Kudus; Sunan Gunung Djati di Kadilangu Demak; Sunan Muria di Gunung Muria sebelah utara Kudus.

Dari beberapa tokoh yang telah disebutkan sebelumnya, ada sosok Sunan Gunung Djati. Sunan Gunung Djati, merupakan sosok yang fenomenal di tanah Jawa, adalah bagian dari Walisanga, yang namanya tidak asing lagi bagi masyarakat, selalu mengajarakan agama Islam dengan metode pendidikan berbasis kultural. Beliau mensyiarkan agama Islam melalui medi wayang.

Namun demikian, tidak lengkap kiranya jika membicarakan Walisanga tanpa menyebutkan kontribusi yang telah dilakukan sosok Sunan Gunung Djati yang merupakan tokoh fenomenal dari bagian Walisanga dengan menggunakan budaya dalam pendidikan Islam yang dijalankannya, untuk mengawal keberlangsungan dan keberhasilan Walisanga di pentas sejarah keindonesiaan.

Budaya sejati yang dimilikinya adalah sebagai jati diri bangsa Indonesia, seharusnya kita bangga dengan adanya budaya yang telah diwariskan dan kelak akan dinikmati oleh anak cucu, Presiden pertama Republik Indonesia Bapak Ir. Soekarno pernah berkata, Bangsa yang besar adalah bangsa yang menghormati jasa pahlawannya. Seperti para Auliya' yang telah mengenalkan agama Islam di pulau Jawa.

Peran dari para Auliya' dalam mensyiarkan agama Islam di bumi pertiwi, tidak bisa dikatakan tidak ada hambatan yang berarti, bagaimana cara para wali menanamkan kepercayaan baru kepada masyarakat yang sudah memiliki kepercayaan jauh sebelumnya ditanamkan pada diri, apabila digambarkan dengan merenovasi bangunan dengan merekonstruksi ulang fondasi mereka.

Menurut Ensiklopedi Ulama Nusantara, Syarif Hidayatullah dilahirkan pada tahun 1448 dari perkawinan Raja Abdullah (Syarif Abdullah) dengan Rara Santang Putri Prabu Siliwangi asal Pajajaran, yang bergelar Syarifah Mudaim. Dilahirkan di Mesir. Pada usia ke-120 tahun, Syarif Hidayatullah (tahun 1568) dipanggil sang Khalik dan dikebumikan di Gunung Sembung Cirebon. Syarif Hidayatullah masih termasuk keturunan Rasulullah SAW. urutan ke-22 sama dengan Sunan Bonang dan Sunan Drajat atau Sunan Giri. (Suprapto, 2009).

Menurut Purwaka Caruban Nagari, pada masa remajanya, ketika umur 20 tahun Syarif Hidayatullah telah berguru kepada Syekh Tajudin al-Kubri selama 2 tahun dan Syekh Ataillahi Syazally yang bermazhab Syafei. Guru-guru Syarif Hidayatullah lainnya adalah Syekh Nur Jati (Datuk Khafidz), Sunan Ampel, Syekh Najmurini (Nujumuddin) Kubra di Mekkah, Syekh Sidiq, Syekh Bentong, dan Syekh Quro. Amman N. Wahju 
1348 Metode Pembayaran Agama Islam Sunan Gunung Djati dalam Perspektif Pendidikan Islam Modern-Asep Supriatna, Rini Novianti Yusuf, Vina Febiani Musyadad, Alfian Syach, Yogha Zulvian Iskandar

DOI : https://doi.org/10.31004/edukatif.v3i4.478

dalam (Nor \& Hasani, 2017).

Pernikahan Syarif Hidayatullah pernah beberapa kali; Retna Pakungwati (Putri Pangeran Cakrabuana) dikaruniai dua anak: Ratu Ayu (istri Fatahillah) dan Pangeran Pesarean (Dipati Muhammad Arifin); pernikahan kedua denngan Ong Tien (Putri Cina, berganti nama Rara Sumanding, tidak berlangsung lama, karena meninggal dunia); ketiga dengan Nyi Mas Retna Babadan (Putri Ki Gedeng Babadan); keempat dengan Dewi Kawunganten (Putri Ki Gedeng Kawunganten, Banten) dikaruniai dua anak; Ratu Winaon dan Pangeran Maulana Hasanuddin (Sultan Banten I); kelima dengan Nyi Mas Rara Kerta (Putri Ki Gedeng Jatimerta) dikaruniai dua anak; Pangeran Jaya Lelana dan Pangeran Brata Lelana. (Suprapto, 2009).

Silsilah Syarif Hidayatullah dari jalur ayah sampai pada Rasulullah SAW, secara singkat sebagai berikut; Rasulullah SAW. mempunyai seorang putri bernama Siti Fatimah yang berputra Sayid Husein yang berputra Zainal Abidin yang berputra Syekh Zainal Kabir yang berputra Syekh Jumadil Kubra dari Quswa yang berputra Raha Umrah-Raja Odhara dari Mesir yang berputra Sultan Bani Israil yang berputra Syarif Hidayatullah. Amman N. Wahju dalam (Nor \& Hasani, 2017). Adapun silsilah Syarif Hidayatullah dari jalur ibu sampai ke Prabu Bunisora. Sang Prabu mempunyai anak Kigedeng Kasmaya (Ki Ageng Giridewata) Penguasa Carbon Girang yang mempunyai putrid Nyi Karancang Singapuri dari Pulo Pinang/Singapura menikah dengan Ki Gedeng Tapa (Ki Gedeng Juman Jati, Juru Labuhan Muarajati II) mempunyai anak Nyi Subang Larang yang menikah dengan Prabu Siliwangi. Dari pernikahannya dengan Prabu Siliwangi mempunyai tiga anak; Pangeran Cakrabuana, Sari Kabun (Rara Santang, Syarifah Mudaim), dan Raja Sangara. Rara Santang menikah dengan Sultan Bani Israil (Sultan Hud, Sultan Mahmud). Dari pernikahannya dengan Sultan Mahmud mempunyai dua putra; Syarif Hidayatullah dan Syarif Nurullah.

Adapun beberapa ajarannya melalui pesan, antara lain sebagai berikut:

a. Pesan Syekh Najmuddin Kubra kepada Syarif Hidayatullah

"Mapam kita iki ing ngahurip. sira aja angebat-tebat ing laku den teka patine. Yen ngucap kang satuhu, lan aja nyerang hukuming Widhi, iku samono kang nyata den kukuh laku iku”.

(Dalam hidup ini, janganlah kamu bertindak berlebihan, demikian hingga akhir hidup. Kalau bicara, bicaralah yang jujur dan jangan melawan hokum dari Yang Maha Esa, itulah hal yang nyata dan lakukanlah hal itu dengan teguh).

b. Pesan Syekh Athaillah di Sadili kepada Syarif Hidayatullah;

"Perkara lampah kang katiti, sira aja ngebat-tebat. Den basaja sira iku, aja langguk ing wicara, sira aja ilok anglaluwih ing padaning manusa. Iku lampah kang sampurna jati. Pan sira aja susah tatapa ing gunung utawa guane iku dadi takabur. Sira laku tapaha maring ingkang remening jalma. Lan duwea muhung. Wong kang luput den ampura. Mung semana lampah ingkang sejati”.

(Mengenai langkah yang harus dijalani, janganlah kamu berlebihan, hiduplah dengan bersahaja, jangan sombong dalam bicara dan jangan.

berlebihan terhadap sesame manusia. Itulah langkah sempurna yang sejati. Bertapa di gunung atau di gua itu akan menjadikanmu takabur, lakukanlah tapa di tengah ramainya manusia. Milikilah sikap luhur dan maafkan orang yang salah, hanya itulah langkah yang sejati).

(Sunyoto, 2011) dalam analisisnya tentang pendidikan dan pengembangan keilmuan Syarif Hidayatullah, seperti di atas, disebutnya dengan ".diwarnai cerita-cerita absurd yang perlu penafsiran untuk mengetahui kebernaran historisnya". Memang penelitian ini perlu dilanjutkan lagi khusus mengenai guru dan ajaran Syarif Hidayatullah, untuk mendalami apa yang dikatakan Sunyoto tersebut.

Konsep pendidikan modern, yaitu ; pendidikan menyentuh setiap aspek kehidupan peserta didik, pendidikan merupakan proses belajar yang terus menerus, pendidikan dipengaruhi oleh kondisi-kondisi dan pengalaman, baik di dalam maupun di luar situasi sekolah, pendidikan dipersyarati oleh kemampuan dan minat peserta didik, juga tepat tidaknya situasi belajar dan efektif tidaknya cara mengajar. Pendidikan pada masyarakat modern atau masyarakat yang tengah bergerak ke arah modern (modernizing), seperti masyarakat 
1349 Metode Pembayaran Agama Islam Sunan Gunung Djati dalam Perspektif Pendidikan Islam Modern-Asep Supriatna, Rini Novianti Yusuf, Vina Febiani Musyadad, Alfian Syach, Yogha Zulvian Iskandar

DOI : https://doi.org/10.31004/edukatif.v3i4.478

Indonesia, pada dasarnya berfungsi memberikan kaitan antara anak didik dengan lingkungan sosial kulturalnya yang terus berubah dengan cepat (Mahfudin et al., 2017).

(Kesuma, 2017) bahwa fungsi pokok pendidikan dalam masyarakat modern yang tengah membangun terdiri dari tiga bagian : (1) sosialisasi, (2) pembelajaran (schooling), dan (3) pendidikan (education). Pertama, sebagai lembaga sosialisasi, pendidikan adalah wahana bagi integrasi anak didik ke dalam nilai-nilai kelompok atau nasional yang dominan. Kedua, pembelajaran (schooling) mempersiapkan mereka untuk mencapai dan menduduki posisi sosial-ekonomi tertentu dan, karena itu, pembelajaran harus dapat membekali peserta didik dengan kualifikasi-kualifikasi pekerjaan dan profesi yang akan membuat mereka mampu memainkan peran sosial-ekonomis dalam masyarakat. Ketiga, pendidikan merupakan "education" untuk menciptakan kelompok elit yang pada gilirannya akan memberikan sumbangan besar bagi kelanjutan program pembangunan."

Dalam menghadapi peradaban modern, yang perlu diselesaikan adalah persoalan-persoalan umum internal pendidikan Islam yaitu (1) persoalan dikotomik, (2) tujuan dan fungsi lembaga pendidikan Islam, (3) persoalan kurikulum atau materi. Ketiga persoalan ini saling interdependensi antara satu dengan lainnya. Pertama, Persoalan dikotomik pendidikan Islam, yang merupakan persoalan lama yang belum terselesaikan sampai sekarang. Pendidikan Islam harus menuju pada integritas antara ilmu agama dan ilmu umum untuk tidak melahirkan jurang pemisah antara ilmu agama dan ilmu bukan agama. Karena, dalam pandangan seorang Muslim, ilmu pengetahuan adalah satu yaitu yang berasal dari Allah SWT. Mengenai persoalam dikotomi, tawaran Fazlur Rahman, salah satu pendekatannya adalah dengan menerima pendidikan sekuler modern sebagaimana telah berkembang secara umumnya di dunia Barat dan mencoba untuk "mengislamkan"nya - yakni mengisinya dengan konsep-konsep kunci tertentu dari Islam. Lebih lanjut persoalannya adalah bagaimana melakukan modernisasi pendidikan Islam, yakni membuatnya mampu untuk produktivitas intelektual Islam yang kreatif dalam semua bidang usaha intelektual bersama-sama dengan keterkaiatan yang serius kepada Islam.

Bila konsep dualisme dikotomik berhasil ditumbangkan, maka dalam jangka panjang sistem pendidikan Islam juga akan berubah secara keseluruhan, mulai dari tingkat dasar sampai ke perguruan tinggi. Untuk kasus Indonesia, IAIN missal nya akan lebur secara integratif dengan perguruan tinggi-perguruan tinggi negeri lainnya. Peleburan bukan dalam bentuk satu atap saja, tetapi lebur berdasarkan rumusan filosofis.

Kedua, perlu pemikiran kembali tujuan dan fungsi lembaga-lembaga pendidikan Islam yang ada. Memang diakui bahwa penyesuaian lembaga-lembaga pendidikan akhir-akhir ini cukup mengemberikan, artinya lembaga-lembaga pendidikan memenuhi keinginan untuk menjadikan lembaga-lembaga tersebut sebagai tempat untuk mempelajari ilmu umum dan ilmu agama serta keterampilan. Tetapi pada kenyataannya penyesuaian tersebut lebih merupakan peniruan dengan pola tambal sulam atau dengan kata lain mengadopsi model yang dilakukan oleh lembaga-lembaga pendidikan umum, artinya ada perasaan harga diri bahwa apa yang bisa dilakukan oleh lembaga-lembaga pendidikan umum dapat juga dilakukan oleh lembaga-lembaga pendidikan agama, sehingga akibatnya beban kurikulum yang terlalu banyak dan cukup berat dan terjadi tumpang tindih. Sebenarnya lembaga-lembaga pendidikan Islam harus memilih satu di antara dua fungsi, apakah mendisain model pendidikan umum Islami yang handal dan mampu bersaing dengan lembagalembaga pendidikan yang lain, atau mengkhususkan pada disain pendidikan keagamaan yang berkualitas, mampu bersaing, dan mampu mempersiapkan mujtahid-mujtahid yang berkualitas.

Ketiga, persoalan kurikulum atau materi Pendidikan Islam, meteri pendidikan Islam "terlalu dominasi masalah-maslah yang bersifat normatif, ritual dan eskatologis. Materi disampaikan dengan semangat ortodoksi kegamaan, suatu cara dimana peserta didik dipaksa tunduk pada suatu "meta narasi" yang ada, tanpa diberi peluang untuk melakukan telaah secara kritis. Pendidikan Islam tidak fungsional dalam kehidupan sehari-hari, kecuali hanya sedikit aktivitas verbal dan formal untuk menghabiskan materi atau kurikulum yang telah diprogramkan dengan batas waktu yang telah ditentukan. 
1350 Metode Pembayaran Agama Islam Sunan Gunung Djati dalam Perspektif Pendidikan Islam Modern-Asep Supriatna, Rini Novianti Yusuf, Vina Febiani Musyadad, Alfian Syach, Yogha Zulvian Iskandar

DOI : https://doi.org/10.31004/edukatif.v3i4.478

Mencermati persoalan yang dikemukakan di atas, maka perlu menyelesaikan persoalan internal yang dihadapi pendidikan Islam secara mendasar dan tuntas. Sebab pendidikan sekarang ini juga dihadapkan pada persoalan-persoalan yang cukup kompleks, yakni bagaimana pendidikan mampu mempersiapkan manusia yang berkualitas, bermoral tinggi dalam menghadapi perubahan masyarakat yang begitu cepat, sehingga produk pendidikan Islam tidak hanya melayani dunia modern, tetapi mempunyai pasar baru atau mampu bersaing secara kompettif dan proaktif dalam dunia masyarakat modern. Pertanyaannya, disain pendidikan Islami yang bagaimana? yang mampu menjawab tantangan perubahan ini, antara lain: Pertama, lembagalembaga pendidikan Islam perlu mendisain ulang fungsi pendidikannya, dengan memilih apakah (1) model pendidikan yang mengkhususkan diri pada pendidikan keagamaan saja untuk mempersiapkan dan melahirkan ulama-ulama dan mujtahid-mujtahid tangguh dalam bidangnya dan mampu menjawab persoalan-persoalan aktual atau kontemporer sesuai dengan perubahan zaman, (2) model pendidikan umum Islami, kurikulumnya integratif antara materi-materi pendidikan umum dan agama, untuk mempersiapkan intelektual Islam yang berfikir secara komprehensif, (3) model pendidikan sekuler modern dan mengisinya dengan konsep-konsep Islam, (4) atau menolak produk pendidikan barat, berarti harus mendisain model pendidikan yang betul-betul sesuai dengan konsep dasar Islam dan sesuai dengan lingkungan sosial-budaya Indonesia, (5) pendidikan agama tidak dilaksanakan di sekolah-sekolah tetapi dilaksanakan di luar sekolah, artinya pendidikan agama dilaksanakan di rumah atau lingkungan keluarga dan lingkungan masyarakat berupa kursur-kursus, dan sebagainya. Kedua disain "pendidikan harus diarahkan pada dua dimensi, yakni : (1) dimensi dialektika (horisontal), pendidikan hendaknya dapat mengembangkan pemahaman tentang kehidupan manusia dalam hubungannya dengan alam atau lingkungan sosialnya.

Secara umum pendidikan Islam pada zaman Sunan Gunung Djati terjadi pasang surut, melihat masuknya agama Islam yang masih sulit, dikarenakan agama Islam adalah agama pendatang. Pada masa kerajaan Cirebon pendidikan hanya dijadikan nomor kesekian bagi rakyat, karena mereka merasa hanya perlu untuk mengabdi kepada raja, kecuali orang bangsawan yang dapat mengenyam pendidikan, karena anaknya akan menggantikan posisi orang tuanya yang menjadi pejabat di kerajaan.

Hal inilah yang dirasa perlu oleh Sunan Gunung Djati, ingin memberikan perhatian lebih kepada rakyat kecil dengan membebaskannya dari pembayaran pajak, dan memberikan santunan meskipun mereka penganut Agama yang tidak sejalan dengan beliau. Dan ketika menjadi pemimpin kerajaan Cirebon Sunan Gunung Djati berpendapat, "menurut saya mulai sekarang sebaiknya kita harus mencari dukungan Rakyat, dan menjalin kerja sama dengan para kerajaan yang berbasis Islam, seperti dikawasan pantai utara Jawa. Selain Itu, kita semua hendaknya tetap menumbuhsuburkan usaha syiar Islami, bahkan dengan menghidupkan pendidikan Informal melalui pesantren". (Susetya, 2010)

Keterangan diatas adalah sebuah bentuk sensitifitas sosial dan keperihatinan yang mendalam dari para cendikiawan muslim yang melihat kondisi pendidikan pada saat itu. Pada hakikatnya mereka menyadari bahwa pendidikan merupakan salah satu tiang yang sangat penting untuk di perhatikan dengan serius dan serta dikembangkan dengan maksimal. Karena hanya dengan pendidikanlah martabat suatu bangsa akan dapat kembali. Oleh karena itu, Sunan Gunung Djati hadir di tengah-tengah keterpurukan pendidikan di Indonesia pada masa itu. Beliau datang dengan segudang pemahaman tentang agama, sosial, dan juga tentang ilmu pendidikan. Dengan rasa ikhlas dan penuh dengan pengabdian kepada negara, beliau mencoba memberikan kontribusi dalam dunia pendidikan.

Dalam hal pendidikan, Sunan Gunung Djati memfokuskannya pada tempat terutamanya, yakni, Masjid/Tajug sebagai sarana pembangun daya nalar, dan tempat untuk pemecahan masalah. Sunan Gunung Djati paernah berkata "Masjid bukan saja merupakan (baitullah/rumah Allah) yang dipakai sebagai tempat ibadah kaum Muslimin, tetapi juga wahana problem solving (penyelesaian masalah) yang dihadapi kaum muslimin."(Susetya, 2010) . Kita bisa melihat betapa hebatnya Sunan Gunung Djati, beliau lebih 
1351 Metode Pembayaran Agama Islam Sunan Gunung Djati dalam Perspektif Pendidikan Islam Modern-Asep Supriatna, Rini Novianti Yusuf, Vina Febiani Musyadad, Alfian Syach, Yogha Zulvian Iskandar

DOI : https://doi.org/10.31004/edukatif.v3i4.478

menempatkan pendidikan diurutan pertama dalam pemerintahan/Negara, karena beliau merasa pendidikan itu akan merubah segalanya, dan akan menjadikan sebuah Negara itu maju.

Sunan Gunung Djati juga berperan untuk menghidupkan dan menumbuh suburkan basis pendidikan Agama secara informal kepada rakyat melalui pendidikan pondok pesantren (ponpes). Dalam proses belajarmengajar di pondok pesantren itu, ada dua variabel yang saling berhubungan satu sama lain, yakni antara ustadz (murad) dan santri (murid). Ustadz (murad) adalah guru atau orang yang mengajarkan ilmu agama Islam, sedangkan santri (murid) adalah pelajar atau orang yang belajar agama Islam.

Dari definisi pendidikan Islam yang sudah dikemukakan pada paragraf sebelumnya, maka dapat dideskripsikan tentang beberapa tujuan yang dinginkan oleh Sunan Gunung Djati. Karena dengan mendeskripsikan beberapa tujuan pendidikan Islam, maka dapat diketahui output yang sebenarnya diinginkan oleh Sunan Gunung Djati. Pemikiran Sunan Gunung Djati yang sudah dipaparkan diatas, merupakan respon pragmatis terhadap kondisi ekonomi umat Islam yang tidak menguntungkan pada saat itu. Hal ini berarti bahwa pendidikan Islam merupakan upaya pembinaan pribadi muslim sejati yang bertaqwa, baik sebagai abdi maupun khalifah fil ardhi. Untuk mencapai tujuan ini, proses pendidikan Islam hendaknya mengakomodasi berbagai ilmu pengetahuan, baik umum maupun agama, untuk mempertajam daya intelektualitas dan memperkokoh spritualitas peserta didik. Dari uraian tersebut, nyatalah bahwa Sunan Gunung Djati benarbenar seorang pemikir dan pembaharu dalam dunia pendidikan Islam. Pemikiran-pemikirannya tentang pendidikan telah menjangkau pola pemikiran modern, dan menumbuhkan semangat pendidikan pada sekarang ini. Misalnya dalam pelaksanaan pendidikan yang terkait dengan penyebaran agama Islam, Sunan Gunung Djati telah berhasil memadukan materi pendidikan agama Islam dan budaya, kemudian memperkokoh kepribadian muslim yang menjadikan cikal bakal pembaharu pendidikan agama Islam pada masa sekarang ini. Hal ini sesuai dengan pola pengembangan pendidikan mutakhir yang meletakkan tiga validitas. Pertama validitas luar, yaitu sejaumana produk yang dihasilkan memenuhi kebutuhan pangsa pasar, kedua, validitas dalam yang menyangkut dengan proses pembelajaran yang berkaitan sesuai dengan kebutuhan masyarakat, ketiga, pembentukan kepribadian yang kokoh yang sesuai dengan tuntutan dan tuntunan ajaran Islam.

Dengan demikian, nampaklah bahwa langkah-langkah pembaharuan yang bersifat "reformasi" yang dilakukan Sunan Gunung Djati, dengan merintis lembaga pendidikan Islam informal lewat pesantren yang didirikan di sekitar kerajaan Demak Bintoro, dan memberikan pendidikan yang memadukan pelajaran agama dan budaya. gagasan pendidikan yang dipelopori Sunan Gunung Djati, merupakan perubahan dan pembaruan karena mampu mengintegrasikan aspek nilai-nilai agama dan budaya, sehingga dihasilkan sosok generasi muslim yang mampu hidup di zaman modern tanpa terpecah kepribadiannya, dan menegakkan agama Islam dimanapun berada dengan tidak mengedepankan fisik akan tetapi kecerdasan akal.

Oleh karena itu, pendidikan hendaknya diletakkan pada skala prioritas dalam proses pembangunan umat. Adapun kunci untuk meningkatkan kemajemukan umat Islam adalah dengan kembali kepada Al-Qur'an dan Al-Sunnah, mengarahkan umat pada pemahaman ajaran Islam secara komprehensif, dan menguasai berbagai disiplin ilmu pengetahuan, sehingga peradaban Islam akan terus berkembang dan akan tetap dipandang oleh negara-negara lain.

Maka dalam menetapkan tujuan pendidikan Islam juga sebagaimana yang telah ditetapkan oleh Al-Qur an yaitu sesuai dengan tujuan penciptaan manusia yaitu sebagai hamba Allah dan khalifah Allah di muka bumi, dalam ungkapan lain disebut dengan rehumanisasi yaitu mengembalikan kedudukan manusia kepada kedudukan yang sebenarnya yaitu sebagai hamba Allah dan Khalifah Allah di muka bumi. Untuk tercapainya tujuan pendidikan Islam tersebut, manusia harus mengembangkan potensi dirinya melalui pendidikan. Potensi diri itu sebagaimana yang dianugerahkan oleh Allah antara lain; fitrah beragama, potensi akal, roh, qalbu dan nafs.

Prinsip Al-Qur'an dan Al-Sunnah yang dipegang teguh oleh Sunan Gunung Djati tidak hanya terlihat dalam dunia pendidikan, akan tetapi juga terlihat dalam kondisi sosial masyarakat pada waktu itu. 
1352 Metode Pembayaran Agama Islam Sunan Gunung Djati dalam Perspektif Pendidikan Islam Modern-Asep Supriatna, Rini Novianti Yusuf, Vina Febiani Musyadad, Alfian Syach, Yogha Zulvian Iskandar

DOI : https://doi.org/10.31004/edukatif.v3i4.478

Sebagaimana yang dikemukakan olehnya, beliau berpendapat bahwa masyarakat akan menjauh jika diserang pendiriannya. Maka mereka harus didekati secara bertahap : mengikuti sambil mempengaruhi. Sunan Gunung Djati berkeyakinan jika Islam sudah dipahami, dengan sendirinya kebiasaan lama hilang. Betapapun bagusnya suatu program pendidikan Islam, jika tidak dibarengi dengan mencoba mengelaborasikan ayat-ayat Al-Qur'an dengan langsung mempraktikan dalam alam nyata dari hasil pemahan dari sebuah ayat tersebut, maka pendidikan Islam yang diajarkan tidak berguna sama sekali. Karena agama Islam akan dapat difahami jika telah dipraktikkan pada kehidupan sehari - hari, Karena itu, Sunan Gunung Djati mencoba mengelaborasikan ayat-ayat Al-Qur'an dengan langsung mempraktikan dalam alam nyata dari hasil pemahaman dari sebuah ayat 1 Surat Al-Alaq :

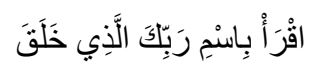

Artinya : Bacalah dengan (menyebut) nama Tuhanmu yang Menciptakan, (QS: Al-A'alaq ayat 1)

(Depag RI, 1998)

Dengan ayat tersebut, Sunan Gunung Djati melihat pentingnya pendidikan, sebagaimana yang diserukan pada surat Al-Alaq ayat 1, berarti agama memerintahan untuk membaca, atau belajar, ini merupakan ayat pertama yang diterima Rasulullah SAW, dengan berdasarkan pengalaman dari Sunan Gunung Djati yang telah berguru pada beberapa guru, beliau mendirikan pesantren, dan mengajarkan agama Islam pada rakyat miskin yang tertindas, dengan memberikan hiburan yang tentunya dengan memasukkan unsurunsur ajaran agama Islam.

Sejalan dengan itu maka pendidikan agama (Islam) sebagai suatu tugas dan kewajiban pemerintah dalam mengemban aspirasi rakyat, harus mencerminkan dan menuju ke arah tercapainya masyarakat pancasila dengan warna agama. Dalam kegiatan pendidikan, agama dan pancasila harus dapat mengisi dan saling menunjang. Pancasila harus dapat meningkatkan dan mengembangkan kehidupan beragama, termasuk pendidikan agama. Ini berarti bahwa pendidikan Islam itu, selain belandaskan Al-Quran, Sunnah, Ijma', dan Qiyas juga berlandaskan pancasila yang kemudian dengan didasari ijtihad dalam menyesuaikan kebutuhan bangsa yang selalu berubah dan berkembang.

Pada zaman keraton Cirebon, kekuasaan ada di tangan Raja, urusan keagamaan diserahkan para wali, dan dinamika kebudayaan masih tumbuh subur di tengah - tengah rakyat. Sunan Gunung Djati bisa memadukan ketiganya dengan selaras, serasi dan seimbang. (Purwadi, 2012). Tiga hal tersebut yang harus dimiliki oleh seorang guru, karena seorang guru adalah agen of cange, yang mendidik seseorang dengan ilmu dan kasih sayang, momong yang berarti mengasuh, mengasuh dalam hal pendidikan, seperti halnya seorang ibu yang mengasuh anaknya agar menjadi anak yang sholeh, momor, bergaul atau bersosialisasi, dalam pendidikan bukankah kita bersinggungan terus menerus dengan masyarakat, pendidikan akan dapat diterima jika seorang guru dapat menyesuaikan diri dan beradaptasi dengan masyarakat. Sosialisasi merupakan hal yang sangat penting bagi keberlangsungan pendidikan. Momot, menampung aspirasi dan inspirasi, seorang guru harus mampu memberikan inspirasi kepada anak didiknya. Makna sumbangsih penelitian Metode penyebaran agama islam sunan gunung djati yang telah di uraikan pada pembahasan ini memberikan sumbangsih pada kemajuan ilmu pengetahuan, karena penelitian ini dapat dijadikan bahan rujukan atau sumber referensi dalam menjalankan pendidikan islam modern yang disesuaikan dengan perkembangan jaman saat ini. Hal ini karena melalui ajaran islam Syarif Hidayatullah mengajarkan tatacara berdoa dan membaca mantera, tatacara pengobatan, serta tatacara membuka hutan yang dapat dipraktekan pada kehidupan seharihari dan disesuaikan dengan perkembangan saat ini. 
1353 Metode Pembayaran Agama Islam Sunan Gunung Djati dalam Perspektif Pendidikan Islam Modern-Asep Supriatna, Rini Novianti Yusuf, Vina Febiani Musyadad, Alfian Syach, Yogha Zulvian Iskandar

DOI : https://doi.org/10.31004/edukatif.v3i4.478

\section{KESIMPULAN}

Berdasarkan hasil penelitian di lapangan yang diperoleh dari hasil observasi, dan studi literatur, maka peneliti menyimpulkan beberapa hal sebagai berikut: 1) Penyebaran Agama Islam yang dilakukan Sunan Gunung Djati terhadap perkembangan Islam di Jawa sangat besar. Beberapa contohnya, adanya kerajaan Islam di Demak dan Banten. Tak kalah pentingnya kontribusi Syarif Hidayatullah pada perkembangan Islam di Jawa Barat melalui dakwah secara damai, mulai dari Kuningan, Indramayu, Majalengka, Cianjur, Garut, Ciamis, Sumedang, bahkan Jayakarta (Betawi). 2) Konsep Pendidikan Menurut Pendidikan Islam sekarang ini disainnya tidak lagi bersifat linier tetapi harus didisan bersifat lateral dalam menghadapi perubahan zaman yang begitu cepat dan tidak terpolakan. 3) Penyebaran Agama Islam Sunan Gunung Djati terhadap Pendidikan Islam Modern sangat relevan. Sunan Gunung Djati adalah seorang pemikir dan pembaharu dalam dunia pendidikan Islam. Pemikiran-pemikirannya tentang pendidikan telah menjangkau pola pemikiran modern, dan menumbuhkan semangat pendidikan sampai sekarang.

\section{UCAPAN TERIMA KASIH}

Terima kasih kepada ketua dan pihak terkait STIT Rakeyan Santang atas dukungan dan partisipasinya sehingga penelitian ini dapat berjalan dengan lancar.

\section{DAFTAR PUSTAKA}

Arikunto, S. (2013). Metode Penelitian kuantitatif kualitatif dan R\&D. Alfabeta: Bandung.

Firmanto, A. (2015). Historiografi Islam Cirebon (Kajian Manuskrip Sejarah Islam Cirebon). Jurnal Lektur Keagamaan, 13(1), 31-58.

Imelda, A. (2017). Implementasi Pendidikan Nilai Dalam Pendidikan Agama Islam. Al-Tadzkiyyah: Jurnal Pendidikan Islam, 8(2), 227-247.

Kesuma, G. C. (2017). Pemberdayaan Pendidikan Islam dalam Upaya Mengantisipasi Kehidupan Masyarakat Modern. Al-Tadzkiyyah, 8(1), 177531.

Mahfudin, R., Wajdi, F., \& Ismail, Y. (2017). Konsep pendidikan Islam KH Abdullah bin Nuh dan Relevansinya Dengan Pendidikan Islam Modern. Jurnal Studi Al-Qur'An, 13(2), 143-157.

Moleong, L. J. (2019). Metodologi penelitian kualitatif.

Nata, D. R. H. A. (2016). Ilmu pendidikan islam. Prenada Media.

Nor, M. R. M., \& Hasani, C. M. (2017). Sumbangan Syarif Hidayatullah dalam Penyebaran Pendidikan Agama Islam di Jawa Barat. At-Ta'dib, 12(1), 173-193.

Purwadi. (2012). Kamus Sansakerta Indonesia.

Putra, N., \& Lisnawati, S. (2012). Penelitian Kualitatif Penelitian Agama Islam. Bandung: Remaja Rosda Karya.

Subagyo, P. J. (2015). Metode Penelitian dalam Teori dan Praktik, cet. Ketujuh. Jakarta: Rineka Cipta.

Sugiyono. (2011). Metode Penelitian Pendidikan.

Sunyoto, A. (2011). Wali songo: rekonstruksi sejarah yang disingkirkan. Transpustaka.

Suprapto, B. (2009). Ensiklopedi ulama Nusantara: riwayat hidup, karya, dan sejarah perjuangan 157 ulama Nusantara. Gelegar Media Indonesia.

Susetya, W. (2010). Sembah raga hingga sembah rasa: menemukan hakikat dalam praktik penghambaan. 
1354 Metode Pembayaran Agama Islam Sunan Gunung Djati dalam Perspektif Pendidikan Islam Modern-Asep Supriatna, Rini Novianti Yusuf, Vina Febiani Musyadad, Alfian Syach, Yogha Zulvian Iskandar DOI : https://doi.org/10.31004/edukatif.v3i4.478

Tajuddin, Y. (2017). ADDIN: WALISONGO DALAM STRATEGI KOMUNIKASI DAKWAH. 